\title{
Resistance Training Supplements and their Potential Benefit
}

\section{Lawrence D Hayes ${ }^{1,2}$, Catherine E Baker ${ }^{1}$, Gordon F Bickerstaff ${ }^{3}$ and Julien S Baker ${ }^{2 *}$}

${ }^{1}$ School of Human Sciences, London Metropolitan University, UK

${ }^{2}$ Institute of Clinical Exercise and Health Science, University of the West of Scotland, UK

${ }^{3}$ Department of Biology, University of the West of Scotland, UK

\begin{abstract}
Resistance Exercise (RE) is a widely practiced activity both in leisure time and in training periods for competitive athletes. Recent advanced in molecular biology and muscle physiology has elucidated some of the mechanisms that regulate muscle growth. As a result of these biochemical advances, an increased number of supplements claiming to enhance adaptations to Resistance exercise have become available. Essentially, the aim of these supplements is to influence protein synthesis and therefore gradual protein accretion leading to increased muscle size and strength. The aim of this review is to discuss the most commonly consumed supplements associated with RE and make recommendations with regards to timing, volume and combinations of supplementations.
\end{abstract}

Keywords: Creatine; Protein; Carbohydrate; $\beta$-alanine; Weight training

\section{Introduction}

Resistance exercise (RE) is one of the most widely practiced forms of physical activity. This type of exercise is often used to enhance athletic performance, augment musculo-skeletal health, and alter body aesthetics. The health benefits of RE are primarily preventative or as a countermeasure to circumstances where muscle weakness compromises optimal function (injury or prolonged inactivity, sarcopenia or musculo-skeletal disorders) however, it can also have a positive effect on skeletal and general metabolic health as well as possible psychological benefits. This review will consider dietary factors that can influence the outcomes of RE, and will review current recommendations for favourable physiological \& biochemical adaptation.

Nutrient intake before, during, and after training will support the adaptations that occur in response to the training stimulus [1]. The effect of nutrition on adaptations that arise from training may not be as important as the training itself, but the effect on the final outcome is important. In recent years, the effect of nutrition on training adaptations has received increasing attention, particularly with respect to maximising the benefits of RE. Consequently the nutritional supplements industry has expanded to become a multi-million dollar industry with an array of products for enhancement of both nutritional status and capacity for increased RE. This review will consider current opinion and practical advice on some of the key macronutrients of a standard diet, and the most commonly used supplements associated with RE.

\section{Protein}

Proteins are synthesised from 20 amino acid building blocks, and to ensure continuity of the synthesis of a given protein, the amino acids are collected in pools to ensure continuous availability for protein synthesis. The absence of any one amino acid from a pool results in immediate cessation of protein synthesis associated with that pool. To avoid a situation where amino acid shortage causes failure of essential protein synthesis, most proteins in the body are in a state of constant turnover (synthesis and degradation) to facilitate constant top up of amino acid pools. Typically a male body of $70 \mathrm{~kg}$ contains about $12 \mathrm{~kg}$ of protein, and $200 \mathrm{~g}$ of free amino acids. Roughly $120 \mathrm{~g}$ of free amino acids are located in skeletal muscle and around $5 \mathrm{~g}$ of free amino acids are found in circulation. Backup support is provided by a suite of transaminase enzymes that can both interchange amino acids, and produce amino acids from simple carbohydrates to make up any shortfall in amino acid pools (Figure 1). Of the 20 amino acids, 12 are designated non-essential in adults because they are readily synthesised as required, and 8 are designated essential and must be supplied in the diet (Table 1).

Protein has long been considered the most vital macronutrient to

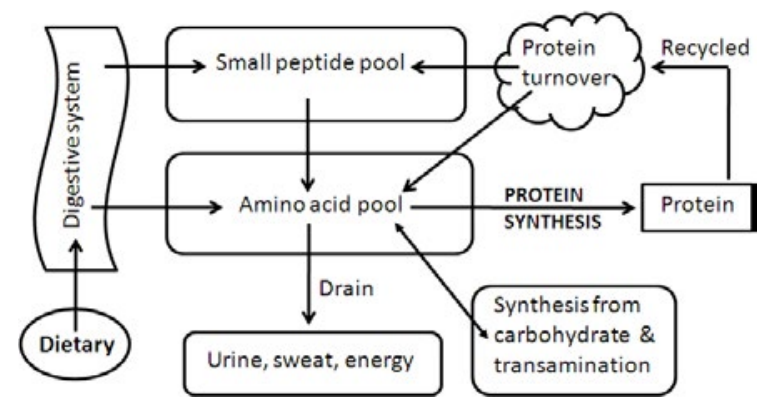

Figure 1: Amino acid pool showing sources of synthesis and degradation.

\begin{tabular}{|c|c|}
\hline Non-essential & Essential \\
\hline Alanine & Arginine ${ }^{*}$ \\
\hline Asparagine & Histidine \\
\hline Aspartate & Isoleucine \# \\
\hline Cysteine\# & Leucine \\
\hline Glutamate & Lysine \\
\hline Glutamine & Methionine \\
\hline Glycine & Phenylalanine \\
\hline Proline & Threonine \\
\hline Serine & Tryptophan \\
\hline Tyrosine & Valine \# \\
\hline
\end{tabular}

( ${ }^{*}$ only in growing young, not in adults)

(\# BCAA branched chain amino acid)

Table 1: Non-essential and essential amino acids.

*Corresponding author: Julien S Baker, Professor, Institute of Clinical Exercise and Health Science, University of the West of Scotland, Lanarkshire, Scotland, UK Tel: 01698 283100; Fax: 01698 894404; E-mail: jsbaker@uws.ac.uk

Received September 18, 2013; Accepted November 20, 2013; Published November 27, 2013

Citation: Hayes LD, Baker CE, Bickerstaff GF, Baker JS (2013) Resistance Training Supplements and their Potential Benefit. J Sports Med Doping Stud 3: 131. doi: $10.4172 / 2161-0673.1000131$

Copyright: $\odot 2013$ Hayes LD, et al. This is an open-access article distributed under the terms of the Creative Commons Attribution License, which permits unrestricted use, distribution, and reproduction in any medium, provided the original author and source are credited. 
facilitate adaptations to RE especially if hypertrophy and strength gains are targeted. In recent times, individuals seeking increased aerobic power and stamina as well as weight loss have become increasingly concerned with the importance of protein in a diet $[2,3]$. Muscular hypertrophy is a developmental process founded on complex metabolism and signalling events in the body. In normal circumstances the body aims to maintain protein homeostasis by keeping protein anabolism and catabolism in balance. Increased mass of muscle is produced by increased anabolic activity to support synthesis of muscle myofibrillar proteins, and with suitable training regimes, protein homeostasis can be shifted toward adaptations that result in increased muscle mass. A positive change in the relative protein content of muscle requires a shift in major metabolic pathways (including energy) and hormone activity that support anabolic production of protein. A negative change in the relative protein content of muscle can occur when the balance shifts to catabolic activity as in periods of starvation when muscle is actively catabolised to provide amino acids as a source of energy. Exercise and nutrition have strong influences on the relative balance of anabolic and catabolic metabolism of muscle protein [4].

$\mathrm{RE}$ and Endurance Exercise (EE) both produce mixed muscle protein synthesis during the subsequent recovery phase and turnover of mixed muscle proteins is increased following RE [5]. Increased supply of amino acids during this time will ensure that amino acid pools are not depleted and will facilitate better muscle protein synthesis after RE $[4,6]$. This could be achieved with a product supply that creates a temporary hyperaminoacidaemia to increase amino acid delivery to the muscle, transport into the muscle cell, and intracellular amino acid pool top up [7]. Tipton and colleagues reported that increased provision of amino acids was responsible for the elevation of protein synthesis [8]. Kobayashi et al. [9] supported this observation by showing that lower levels of blood amino acids resulted in decreased muscle protein synthesis, and that protein synthesis was restored with restoration of increased blood amino acids. Clearly blood amino acid levels are essential for muscle protein synthesis.

Recent research has focused on the importance of individual amino acids to influence anabolism with leucine receiving most attention $[1,10]$. Leucine is one of the Branched-Chain Amino Acids (BCAA), and is an essential amino acid. Koopman et al. [10] investigated the effects of additional free leucine to a post exercise recovery drink (carbohydrate vs. carbohydrate and protein vs. carbohydrate, protein and leucine). The addition of leucine resulted in an increased plasma insulin response and increased net protein balance when compared with protein ingestion alone. However, Tipton suggests that additional leucine does not have a greater influence in an already anabolic situation following RE plus protein ingestion, and hypothesised that metabolism and hormone actions are already fully activated by RE and amino acids, including leucine, in whey proteins and therefore, no further activation by free leucine is possible $[1,11]$. As a result of these findings, it is unclear whether additional leucine supplementation provides any advantage. It is clear that post exercise recovery of muscle protein synthesis does require leucine, but it is likely that dietary or supplemented protein will provide sufficient amounts of leucine to facilitate synthesis.

Research into the optimum timing of protein and amino acid ingestion has also produced equivocal results $[3,12]$. Tipton et al. reported that protein ingestion pre and post RE both resulted in the change from negative net muscle protein balance to a positive balance [12]. However, the total response to an Essential Amino Acid-Carbohydrate (EAC) solution was greater when consumed immediately pre exercise compared to immediately post. Interestingly, muscle protein metabolism was also elevated for longer when the EAC solution was consumed pre-exercise compared to post. The length of the effect, plus higher blood flow during exercise in the PRE trial, resulted in significantly greater total uptake over the entire study period. A commonly discussed concept in RE and protein ingestion is that of the "metabolic window" (i.e. the $45 \mathrm{~min}-1 \mathrm{~h}$ immediately post $\mathrm{RE})$. It has been suggested that this is the time when consumption of protein is most effective [13]. However, this phenomenon may not be as important as previously thought as Rasmussen et al. demonstrated that the response of muscle to an EAC solution was similar when ingested 1 and $3 \mathrm{~h}$ following RE [14]. Interestingly, Cribb and Hayes reported greater increases in lean body mass, CSA of type II muscle fibres and 1-repetition maximum (1RM) when ingestion of an EAC was immediately pre and post compared to early morning and late evening suggesting that the timing of protein ingestion can enhance the desired adaptations from RE training [13].

While the importance of protein for muscular adaptation is clear and unquestioned, the amount of protein required is controversial. Protein synthesis is elevated post RE and the amount of protein intake should be sufficient to support the increased level of anabolism. Typically the protein requirement of an individual is based on nitrogen balance, which is generally elevated for athletes compared with sedentary individuals [14]. Many coaches and athletes advocate very high protein intake, up to $4.0 \mathrm{gkg}^{-1} \mathrm{day}^{-1}$ [15]. Even the American Dietetic Association, Dieticians of Canada and the American College of Sports Medicine state that protein intake must be $>1.6 \mathrm{gkg}^{-1} \mathrm{day}^{-1}$ for gains in muscle mass [16]. There is another school of thought that protein requirements for active individuals are not increased above that of sedentary controls [3,17]. This argument is supported by the fact that exercise increases the turnover and hence efficiency of amino acid utilisation possibly due to reutilisation of amino acids from muscle protein breakdown to re-supply amino acid pools $[17,18]$. RE trained individuals also exhibit a greater negative net muscle protein balance than untrained volunteers in a fasted state [4]. Tipton proposed that exercise decreases protein requirement. Ratamess and colleagues reported no increased response to a 10 week RE protocol when comparing low $\left(<1.2 \mathrm{gkg}^{-1} \mathrm{day}^{-1}\right)$, moderate $\left(1.21-1.90 \mathrm{gkg}^{-1} \mathrm{day}^{-1}\right)$, and high $\left(>1.91 \mathrm{gkg}^{-1} \mathrm{day}^{-1}\right)$ protein intake in collegiate football players $[1,18]$. Ferrara et al. [19] reported similar findings when examining changes in body composition after a high $\left(1.9 \mathrm{gkg}^{-1} \mathrm{day}^{-1}\right)$ and normal $\left(1.3 \mathrm{gkg}^{-1} \mathrm{day}^{-1}\right)$ protein intake for six months. These findings suggest that high protein intake $\left(>1.9 \mathrm{gkg}^{-1} \mathrm{day}^{-1}\right)$ is unnecessary for gains in muscle mass and that moderate consumption (approximately $1.2-1.9 \mathrm{gkg}$ ${ }^{1}$ day $^{-1}$ ) appears sufficient. Conversely, Hoffman et al. [20] demonstrated a trend for increased lean body mass with protein supplementation of $2.0 \mathrm{gkg}^{-1} \mathrm{day}^{-1}$ compared to $1.2 \mathrm{gkg}^{-1} \mathrm{day}^{-1}$ in collegiate football players. The authors also demonstrated a significant increase in $1 \mathrm{RM}$ squat performance after a 12 week RE program on the higher protein intake compared to moderate consumption. Interestingly, Hoffman et al. [20] did not observe any statistical difference in 1RM bench press, wingate performance, body mass, resting testosterone, insulin-like growth factor-1 (IGF1), or growth hormone (GH) between groups. The combination of these findings suggest that elevated protein intake $>2.0$ $\mathrm{gkg}^{-1} \mathrm{day}^{-1}$ may augment strength development in RE trained individuals however the increase above moderate consumption is likely minimal. The purpose of protein ingestion is to top up amino acid pools that will then support protein synthesis, and it should be recognized that such pools are finite, such that when topped up to the maximum then further protein ingestion will not result in increased pool size. Excess amino acids are eliminated from the body and protein intake above moderate consumption may also be potentially harmful as removal of excess 
amino acids may add stress to the function of the kidneys (Figure 1).

The majority of studies investigating protein consumption on $\mathrm{RE}$ adaptations have not used competitive strength/power athletes directly, but instead seek to extrapolate from various populations what strength/ power athletes need. This is a weakness in such studies and despite the high internal validity of these studies, their practical application to elite and competitive RE athletes is potentially limited.

It is known that not all proteins are equal as sources of amino acids that will support the synthesis of myofibrillar protein. The biological value of a protein is a measure of the efficiency with which a given protein is absorbed and assimilated into the protein of an organism. Milk and egg white are examples of proteins with high biological value, whereas plant sources have a relatively low value due to absence of some essential amino acids. Wilkinson and colleagues demonstrated that fatfree mass was increased to a greater extent in individuals consuming fluid milk (whey and casein) than when a soya protein beverage was consumed [21]. Numerous studies have reported diverse absorption characteristics of whey (rapidly absorbed) and casein (slowly absorbed) proteins [22]. Tang et al. [6] reported that muscle protein synthesis was elevated in a stepwise manner (whey $>$ soy $>$ casein) after exercise and at rest. These authors suggested that to increase muscle anabolism, a rapid increase in essential amino acids (possibly leucine specifically) is required. Yet, the benefit of one over the other is still unknown with regard to RE. Also important is the relationship between muscle and liver as a significant amount of ingested amino acids can be taken up by the liver and oxidized for fuel or used for other metabolic requirements.

From the evidence reviewed, moderate protein consumption (approximately 1.2-1.9 $\mathrm{gkg}^{-1} \mathrm{day}^{-1}$ ) is recommended for individuals partaking in RE for aesthetics or for general health as to date no study has shown favourable anthropometric changes for high consumption over moderate consumption [22]. For elite and competitive athletes higher levels of protein intake may result in weight gain and movement through weight categories, but may be important in supporting and maintaining a high level of protein turnover. Excessively high levels of protein intake will not result in increased protein synthesis due to limitations imposed by amino acid pools, and may be harmful as excess amino acids are removed from the body. With regards to timing of ingestion, immediately pre RE is likely to be more beneficial as this has shown to increase protein synthesis for a longer period than post-RE consumption.

\section{Carbohydrate}

Carbohydrate $(\mathrm{CHO})$ supplementation is common in endurance athletes and provides an exogenous source of glucose [23]. Less importance has been placed on the consumption of $\mathrm{CHO}$ in $\mathrm{RE}$ trained individuals compared with protein. As discussed above, RE stimulates protein synthesis and supply of amino acids can elevate protein synthesis further. It has been suggested that an addition of $\mathrm{CHO}$ to a post exercise protein solution may increase muscle anabolism by taking advantage of the resultant insulin response to $\mathrm{CHO}$. An increase in insulin, as a result of glucose ingestion, would counteract the adenosine monophosphateactivated protein kinase (AMPK) activity which promotes glucose and fatty acid oxidisation for energy and inhibits protein synthesis (Figure 2). AMPK promotes energy release and inhibits energy consumption, and protein synthesis is an energy-demanding process [24]. During exercise, metabolism rightly shifts to the catabolic mechanisms that provide energy for muscle activity. Anabolic activity is curtailed and although insulin is a key anabolic hormone in moving glucose into muscle cells via its regulation of GLUT4, the anabolic activity of insulin during exercise is inhibited.

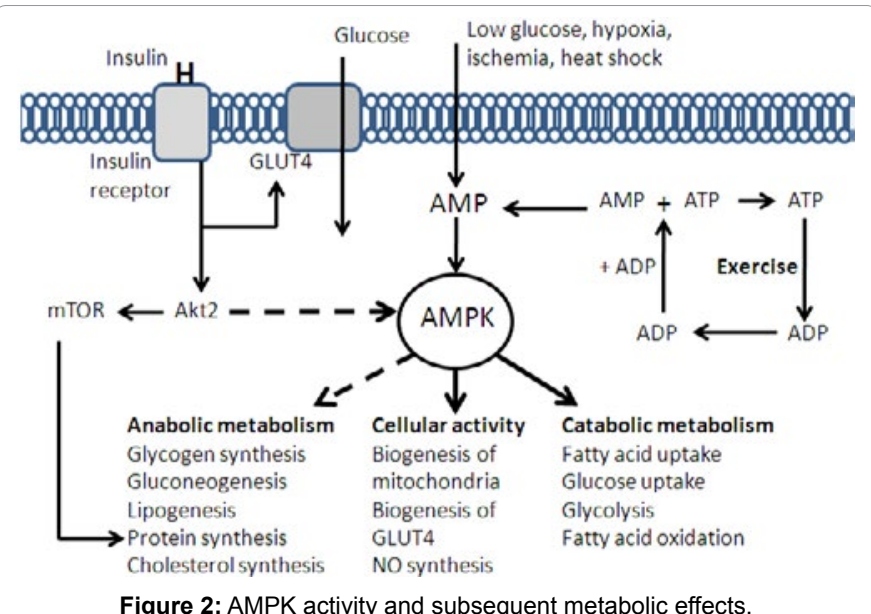

It is the aim during $\mathrm{RE}$ to minimise the reduction in insulin as it has been shown to have significant effect on muscle protein synthesis when adequate amino acid concentrations are available, by reducing protein catabolism [22]. Exercise-induced mRNA transcription and synthesis of proteins is only fully activated when plasma insulin levels are elevated [24]. Elevations in insulin are expected to inhibit AMPK activity, therefore promoting protein synthesis (Figure 2). Insulin exerts its effect on translation through the protein kinase B (Akt2)mammalian target of rapamycin (mTOR) pathway. This response is critical for increasing muscle protein synthesis and subsequent hypertrophy [25]. The mTOR signal serves to increase protein synthesis by increasing the number of messenger RNA translated per ribosome. Insulin concentrations parallel changes in blood glucose, and the response is enhanced when protein and carbohydrates are ingestion prior to, during, or after a workout [26].

It has previously been reported that insulin in the absence of amino acid availability does not stimulate protein synthesis [27]. Therefore, the ingestion of protein with $\mathrm{CHO}$ after exercise should allow insulin to exert its stimulatory effect on muscle, which, according to Ivy and colleagues would likely manifest itself as an interactive effect (i.e. the combined effects of hyperinsulinemia and the exogenous protein would be greater than the sum of their independent effects) [28]. This hypothesis has been both supported and opposed [10,29]. Ivy et al. [28] reported that supplementation with a $\mathrm{CHO}$-protein drink after exercise increased phosphorylation of Akt, mTOR, ribosomal protein S6 and glycogen synthase kinase $3 \alpha / \beta$ when compared to a placebo. This in turn lead to increased release of amino acid into the blood and would theoretically stimulate muscle protein synthesis however this was not measured directly in the study. Interestingly, Ivy et al. [28] examined phosphorylation of these muscle proteins after repeated sprints on a cycle ergometer. It is therefore unclear if any hypertrophy did occur as this type of exercise may or may not result in muscular growth in already conditioned individuals.

Vollestad et al. [29] suggested that intermittent activities (such as $\mathrm{RE})$ can stimulate significant glycogenolytic effects. MacDougall et al. [30] indeed reported that RE can significantly decrease muscle glycogen stores. Therefore, it is commonly accepted that muscle glycogen is an important fuel for RE and maintenance of these stores may enhance performance. Reductions in muscle glycogen have resulted in decreased isokinetic and isometric force production and accentuated exercise-induced muscle weakness [31]. A study by Haff et al. [32] demonstrated that RE-induced decreases in muscle glycogen can be attenuated by $\mathrm{CHO}$ feeding during RE. Haff et al. [32] however, did not 
report enhanced isokinetic leg extension performance with increased muscle glycogen as a result of $\mathrm{CHO}$ supplementation. This result may be a product of the performance test selected as Leveritt and Abernethy reported than decreased muscle glycogen resulted in impaired back squat performance but not isokinetic leg extension [33]. Lambert et al. [34] and Haff and colleagues have reported enhanced RE performance with $\mathrm{CHO}$ supplementation over isokinetic and free-weight testing protocols [35,36]. Conversely, Conley et al. [37] and Vincent et al. [38] reported no benefit of $\mathrm{CHO}$ supplementation on a $\mathrm{RE}$ protocol of high volume. It is important to note that these studies differed significantly in time; studies by Lambert et al. [34] and Haff et al. [35,36] lasted 56, 77, and 57 mins respectively whereas the investigations by Conley et al. [37] and Vincent et al. [38] were much shorter in duration. As exercise bouts lasting less than 41 min rely primarily on muscle glycogen as a fuel source, the increased duration and reliance of exogenous blood glucose may have promoted performance decrements in the three longer duration investigations. It appears from these findings that with increased duration of RE, the probability of decreased performance increases. Notably, these investigations asked participants to perform a $\mathrm{RE}$ session of high volumes of work similar to those performed using a hypertrophy protocol. Therefore the effect of $\mathrm{CHO}$ supplementation on a strength protocol (sets of 1-6RM) is unknown. The literature suggests that $\mathrm{CHO}$ supplementation may be vital to maximise performance of $\mathrm{RE}$ when using large-muscle mass free-weight exercise performed with high training volumes and moderate loads as the amount of glycogen used in these exercise appears to be related to the total amount of work and the duration of the RE protocol. More research is required to provide greater understanding of the effect of $\mathrm{CHO}$ supplementation on RE. To date no studies have concerned the effect of high/low glycemic $\mathrm{CHO}$ on $\mathrm{RE}$, adaptations to chronic $\mathrm{CHO}$ supplementation without addition of protein, a dose-response relationship with $\mathrm{CHO}$ supplementation (dose), and RE performance (response) or the timing of $\mathrm{CHO}$ ingestion (before vs. after RE).

\section{Creatine}

Creatine supplementation has been surrounded by controversy since it gained popularity in the early 1990's [39]. Some anecdotal reports have claimed that creatine has a number of health risks, and is an unnecessary practice. However, many athletes and experts in the field have reported that use of creatine not only enhances exercise performance, but is also clinically safe [40]. In the initial stages of intense exercise when Adenosine Triphosphate (ATP) consumption is high, energy to re-phosphorylate adenosine diphosphate (ADP) to ATP (Figure 3) during and following intense exercise is provided by, and is therefore largely dependent on the amount of, phosphocreatine (PCr) stored in the muscle [41]. High-intensity exercise depletes PCr stores and the rate of energy availability diminishes as a result of reduced rate of ATP production. The capacity for maximal-intensity exercise declines and availability of PCr in muscle dictate energy generation until other mechanisms of ATP production take over. It has been hypothesised that increasing muscle creatine content by exogenous supplementation may allow greater training adaptations because of an enhanced quality

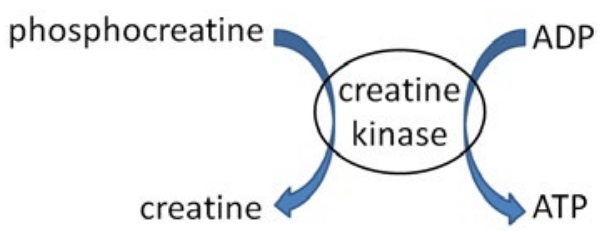

Figure 3: PCr actions. and volume of work performed as a result of an improved rate of ATP resynthesis during high-intensity exercise.

Creatine is synthesised in liver and pancreas from amino acids arginine, methionine, and glycine with approximately $95 \%$ of the body's creatine stored in skeletal muscle [42]. Furthermore, small amounts of creatine can be found in the testes and brain. Approximately two thirds of creatine stored in muscle is stored as $\mathrm{PCr}$ and the rest as free creatine. Approximately $1-2 \%$ of the creatine pool is broken down per day into creatinine in the skeletal muscle and then excreted in urine [41]. Creatine stores can be replenished by dietary intake containing creatine (meat and fish) or through endogenous synthesis of creatine from arginine, methionine, and glycine. Relatively small amounts of creatine are found in meat and fish and therefore supplementation provides a cost effective and simple means of increasing creatine availability without excessive fat, protein or calorific intake. Tarnopolsky et al. compared $10 \mathrm{~g}$ creatine monohydrate and $50 \mathrm{~g} \mathrm{CHO}$ against $10 \mathrm{~g}$ casein protein and $50 \mathrm{~g} \mathrm{CHO}$ and reported that the creatine group reported a greater increase in fat free mass compared to the protein group [43]. The implications of this suggest that in sports where body weight is unimportant, creatine is a superior supplement than casein protein when combined with $\mathrm{CHO}$ to enhance hypertrophy.

Various supplementation protocols have been suggested as effective in increasing muscle stores of muscle creatine. The amount of increase in muscle storage is dependent on creatine levels in the muscle prior to supplementation. Individuals with lower muscle stores may experience storage increases of $20-40 \%$ whereas those with relatively high stores may only increase by $10-20 \%$ [41]. The extent of the increase in skeletal muscle creatine storage is important as studies have reported performance changes to be correlated to this increase [44]. The most commonly described protocol is known as the "loading" protocol; characterised by ingestion of approximately $5 \mathrm{~g}$ four times per day for 5-7 days and 3-5 $\mathrm{g} \cdot \mathrm{d}^{-1}$ thereafter [41]. This protocol has results in an increase of $10-40 \%$ in muscle creatine and PCr stores [45]. Further research has demonstrated that a shorter loading period is still beneficial, as is a reduced dosage, particularly if ingested with $\mathrm{CHO}$ or protein [45]. Other suggested protocols include those with no loading phase as well as "cycling". Cycling protocols typically consist of "loading doses" for 3-5 days every 3-4 weeks. These protocols have been shown to be effective in increasing strength and hypertrophy [46,47]. It would be interesting to compare these protocols within one research paper to establish optimum strategy and determine whether the strategy or the total creatine consumption is the key factor concerning RE adaptations.

Many forms of creatine currently exist in the marketplace within various formulations. However, few of these have shown any benefit over the traditional creatine monohydrate. Recently, Spillane et al. examined the effectiveness of creatine ethyl ester and reported no additional benefit in muscle strength or anthropometry when compared to creatine monohydrate [48]. Similar findings have been reported for creatine phosphate a creatine/ $\beta$-hydroxy- $\beta$-methlybutyrate (HMB) combination and creatine plus glycerol $[42,49,50]$. However, the combination of $\mathrm{CHO}$ and creatine in a formula has been shown to increase muscle creatine retention with Pittas et al. suggesting only a small amount of $\mathrm{CHO}$ is required to optimise insulin-mediated creatine retention [45,51]. These authors also reported that a combination of protein, $\mathrm{CHO}$ and creatine was optimum for insulin response and creatine retention. Other recent studies have indicated a potential benefit to RE when combining creatine with protein [52]. From these findings, it appears that combining creatine with protein and/or $\mathrm{CHO}$ produces optimal results. Despite the trepidation surrounding creatine supplementation, it appears to be the most effective nutritional 
supplement in terms of improving lean body mass and anaerobic capacity. With regard to the medical safety of creatine supplementation, no peer-reviewed paper to date has reported any clinically significant side effect other than weight gain as a result of normal creatine intake $\left(<25 \mathrm{~g} \mathrm{~d}^{-1}\right)$.

\section{$\beta$-Alanine}

The dipeptide carnosine is synthesized in human skeletal muscle and has been shown to contribute increased capacity to buffer hydrogen ions $\left(\mathrm{H}^{+}\right)$during intense exercise [53]. It is synthesized within skeletal muscle from histidine and $\beta$-alanine. While histidine, a non-essential amino acid (in adults), is found in high concentrations along with carnosine synthetase in skeletal muscle $\beta$-alanine, an amino acid derivative, is found in much lower concentrations [54]. Therefore, $\beta$-alanine is likely the rate-limiting step in carnosine synthesis [54]. Increased skeletal muscle carnosine levels through $\beta$-alanine supplementation have been shown to support the maintaintenance acid-base balance, delay fatigue, and improve exercise performance.

A number of investigations concerning the effect of $\beta$-alanine supplementation on EE events suggest that supplementation enhances performance [55]. Less research has been conducted on the efficacy of $\beta$-alanine on RE. Hoffman et al. compared supplementation of creatine with a combination of creatine and $\beta$-alanine in collegiate football players [56]. Addition of $\beta$-alanine appeared to provide a greater training stimulus than creatine alone. Significant improvements were observed for both squat and bench press exercise, lean tissue mass and fat loss in subjects supplementing with both $\beta$-alanine and creatine compared with creatine alone. Interestingly, no differences were noted in the magnitude of strength improvements between the groups. In fact, to date, no research suggests that $\beta$-alanine supplementation improves maximum strength. Hoffman et al. [56] showed no improvements in $1 \mathrm{RM}$ squat exercise after supplementation. Kendrick et al. [57] reported that $\beta$-alanine supplementation did not enhance performance of a box squat, bench press, dead lift or isokinetic leg extension at $180^{\circ} \mathrm{s}^{-1}$. These results are not entirely surprising as $\beta$-alanine supports buffering capacity, and maximal strength is not limited by acidosis. Similarly, Portington et al. [58] also showed that other buffering agents such as sodium bicarbonate also failed to demonstrate any ergogenic effect on strength performance.

The major putative effects of greater buffer capacity are likely to be observed in activities eliciting a high intracellular acidosis. In particular, stronger buffer capacity has been especially ergogenic in multiple bouts of high-intensity short-term exercises interspersed by short recovery intervals [59]. Hoffman et al. [56] showed that $\beta$-alanine supplementation did not enhance maximal strength performance but resulted in a $\sim 20 \%$ increase in total work volume during $\mathrm{RE}$ in welltrained resistance athletes. Conversely, when an exercise protocol elicits a less extreme muscular acidosis (i.e. exercise lasting $<60$ s or exercises using small muscle groups), no beneficial effects of $\beta$-alanine have been observed $[59,60]$.

From the literature concerning $\beta$-alanine to date, it is possible to draw the following conclusions: 1 ) chronic supplementation of $\beta$-alanine can enhance performance of multiple bouts of high-intensity shortterm exercise interspersed by short recovery; 2 ) acute supplementation of $\beta$-alanine appears not to enhance strength performance and; 3 ) total work during RE can be increased through $\beta$-alanine supplementation even in well-trained athletes.

\section{Caffeine}

Caffeine remains the most widely utilised ergogenic aid, and bears a strong evidence base for beneficial use in medium to long duration sports performance. However, the impact of caffeine upon short duration high intensity activity remains unclear; with some studies showing no effect or even a performance decrement with caffeine supplementation [61-63]. Duncan et al. however, reported that number of repetitions completed was higher when caffeine was ingested $60 \mathrm{~min}$ pre-RE [64]. This suggests that total work was higher in the caffeine condition. Therefore, if this phenomenon continued over time, RE adaptation would likely be augmented due to a greater stimulus. However, the study by Duncan et al. only concerned one RE bout and therefore, this is purely speculation. Astorino and Roberson suggest that trained athletes may respond more favourably than untrained participants to ergogenic effects of caffeine in resistance training [65]. Moreover, they suggest that RPE and Pain sensation remain unaffected by caffeine supplementation in short term activity. Like many proposed ergogenic supplements, the magnitude of response varies between individuals and this is arguably owing to different rates of metabolism [66]. The exact mechanism of caffeine, as an ergogenic substance, remains unclear although it is believed that the effector is located outside of the muscle cell thus, acute resistance exercise, where metabolism occurs within the cell, in understandably less affected by caffeine ingestion [65].

\section{Nitrates}

Dietary nitrates have recently attracted attention as a potential ergogenic aid to sports performance. Although there is some support for their use with endurance activity the efficacy of utilisation in short duration resistance exercise remains unsubstantiated [67-69]. This is perhaps unsurprising given their mechanism of impact via cardiorespiratory efficiency. However, as duration of exercise increases, where muscular endurance becomes an important performance factor, nitrate supplementation may yet prove beneficial. Evidence is beginning to support the use of nitrate supplementation, most often in the form of beetroot juice, for high intensity constant workloads; whilst the support for use in intermittent high intensity work remains equivocal [70]. Interestingly, Kelly and Colleagues observed that nitrate supplementation improved exercise tolerance during exercise at 60 , 70 , and $80 \%$ delta, but not $100 \%$ peak power, suggesting that nitrate can improve performance at submaximal intensity but not peak power output [71]. There is some debate as to the primary effector mechanism for the performance gains seen post nitrate supplementation; with suppressed muscular ATP turnover and alterations in mitochondrial efficiency both being posited [69]. Thus, whilst there is no argument for utilising nitrates during resistance training itself, there may be benefits to the athletes involved in resistance training as part of a broader programme for sports performance.

\section{Conclusion}

Availability of amino acids is important for protein synthesis associated with hypertrophy and inclusion of $\mathrm{CHO}$ may maximise the effect of insulin with creatine also increasing lean body mass. Therefore, a combination of $\mathrm{CHO}$, protein and creatine could be beneficial to consume pre-, during-, and post-exercise to maximise hypertrophy and recovery. However, creatine is not recommended for athletes who compete in events that require acceleration of one's own body mass. Of course, acute program variables of the training protocol (volume, load, rest period length, exercise selection, and exercise order) have the largest impact upon adaptations to resistance exercise and these factors must be optimized to maximize resultant physiological modifications. A number of other factors affect adaptations to RE including age, genetics, gender, timing of training periods, posture as well as cultural and general habits. 


\section{References}

1. Tipton KD (2008) Protein for adaptations to exercise training. Eur J Sport Sci 8: $107-118$

2. Jesudason D, Nordin BC, Keogh J, Clifton P (2013) Comparison of 2 weightloss diets of different protein content on bone health: a randomized trial. Am J Clin Nutr 98: 1343-1352.

3. Saunders MJ (2007) Coingestion of carbohydrate-protein during endurance exercise: influence on performance and recovery. Int J Sport Nutr Exerc Metab 17 Suppl: S87-103.

4. Phillips SM, Tipton KD, Ferrando AA, Wolfe RR (1999) Resistance training reduces the acute exercise-induced increase in muscle protein turnover. Am J Physiol 276: E118-124.

5. Tipton KD, Witard OC (2007) Protein requirements and recommendations for athletes: relevance of ivory tower arguments for practical recommendations. Clin Sports Med 26: 17-36.

6. Tang JE, Moore DR, Kujbida GW, Tarnopolsky MA, Phillips SM (2009) Ingestion of whey hydrolysate, casein, or soy protein isolate: effects on mixed muscle protein synthesis at rest and following resistance exercise in young men. J App Physiol (1985) 107: 987-992.

7. Biolo G, Tipton KD, Klein S, Wolfe RR (1997) An abundant supply of amino acids enhances the metabolic effect of exercise on muscle protein. Am J Physiol 273: E122-129

8. Tipton KD, Ferrando AA, Phillips SM, Doyle D Jr, Wolfe RR (1999) Postexercise net protein synthesis in human muscle from orally administered amino acids. Am J Physiol 276: E628-634.

9. Kobayashi H, Børsheim E, Anthony TG, Traber DL, Badalamenti J, et al (2003) Reduced amino acid availability inhibits muscle protein synthesis and decreases activity of initiation factor elF2B. Am J Physiol Endocrinol Metab 284: E488-498.

10. Koopman R, Beelen M, Stellingwerff T, Pennings B, Saris WH, et al. (2007) Coingestion of carbohydrate with protein does not further augment postexercise muscle protein synthesis. Am J Physiol Endocrinol Metab 293: E833-842.

11. Rennie MJ (2007) Exercise- and nutrient-controlled mechanisms involved in maintenance of the musculoskeletal mass. Biochem Soc Trans 35: 1302-1305.

12. Tipton KD, Rasmussen BB, Miller SL, Wolf SE, Owens-Stovall SK, et al. (2001) Timing of amino acid-carbohydrate ingestion alters anabolic response of muscle to resistance exercise. Am J Physiol Endocrinol Metab 281: E197-206.

13. Cribb PJ, Hayes A (2006) Effects of supplement timing and resistance exercise on skeletal muscle hypertrophy. Med Sci Sports Exerc 38: 1918-1925.

14. Rasmussen BB, Tipton KD, Miller SL, Wolf SE, Wolfe RR (2000) An oral essential amino acid-carbohydrate supplement enhances muscle protein anabolism after resistance exercise. J Appl Physiol (1985) 88: 386-392.

15. Alway SE, Grumbt WH, Stray-Gundersen J, Gonyea WJ (1992) Effects of resistance training on elbow flexors of highly competitive bodybuilders. J Appl Physiol (1985) 72: 1512-1521.

16. American College of Sports Medicine; American Dietetic Association; Dietitians of Canada (2000) Joint Position Statement: nutrition and athletic performance. American College of Sports Medicine, American Dietetic Association, and Dietitians of Canada. Med Sci Sports Exerc 32: 2130-2145

17. Phillips SM, Moore DR, Tang JE (2007) A critical examination of dietary protein requirements, benefits, and excesses in athletes. Int J Sport Nutr Exerc Metab 17 Suppl: S58-76.

18. Ratamess NA, Hoffman JR, Faigenbaum AD, Mangine GT, Falvo MJ, et al (2007) The combined effects of protein intake and resistance training on serum osteocalcin concentrations in strength and power athletes. J Strength Cond Res 21: 1197-1203.

19. Ferrara LA, Innelli P, Palmieri V, Limauro S, De Luca G, et al. (2006) Effects of different dietary protein intakes on body composition and vascular reactivity. Eur J Clin Nutr 60: 643-649.

20. Hoffman JR, Ratamess NA, Kang J, Falvo MJ, Faigenbaum AD (2007) Effects of protein supplementation on muscular performance and resting hormonal changes in college football players. J Sports Sci Med 6: 85-92.

21. Wilkinson SB, Tarnopolsky MA, Macdonald MJ, Macdonald JR, Armstrong D et al. (2007) Consumption of fluid skim milk promotes greater muscle protein accretion after resistance exercise than does consumption of an isonitrogenous and isoenergetic soy-protein beverage. Am J Clin Nutr 85: 1031-1040.
22. Tipton KD, Elliott TA, Cree MG, Wolf SE, Sanford AP, et al. (2004) Ingestion of casein and whey proteins result in muscle anabolism after resistance exercise. Med Sci Sports Exerc 36: 2073-2081

23. Phillips SM, Sproule J, Turner AP (2011) Carbohydrate ingestion during team games exercise: current knowledge and areas for future investigation. Sports Med 41: 559-585.

24. Ju JS, Gitcho MA, Casmaer CA, Patil PB, Han DG, et al. (2007) Potentiation of insulin-stimulated glucose transport by the AMP-activated protein kinase. Am J Physiol Cell Physiol 292: C564-572.

25. Hawke TJ (2005) Muscle stem cells and exercise training. Exerc Sport Sci Rev 33: $63-68$.

26. Hather BM, Tesch PA, Buchanan P, Dudley GA (1991) Influence of eccentric actions on skeletal muscle adaptations to resistance training. Acta Physio Scand 143: 177-185.

27. Goto K, Nagasawa M, Yanagisawa O, Kizuka T, Ishii N, et al. (2004) Muscular adaptations to combinations of high- and low-intensity resistance exercises. J Strength Cond Res 18: 730-737.

28. Ivy JL, Ding Z, Hwang H, Cialdella-Kam LC, Morrison PJ (2008) Post exercise carbohydrate-protein supplementation: phosphorylation of muscle proteins involved in glycogen synthesis and protein translation. Amino Acids 35: 89-97.

29. Vøllestad NK, Tabata I, Medbø JI (1992) Glycogen breakdown in differen human muscle fibre types during exhaustive exercise of short duration. Acta Physiol Scand 144: 135-141.

30. MacDougall JD, Ray S, Sale DG, McCartney N, Lee P, et al. (1999) Muscle substrate utilization and lactate production. Can J Appl Physiol 24: 209-215.

31. Yaspelkis BB 3rd, Patterson JG, Anderla PA, Ding Z, Ivy JL (1993) Carbohydrate supplementation spares muscle glycogen during variable-intensity exercise. $J$ Appl Physiol (1985) 75: 1477-1485.

32. Haff GG, Koch AJ, Potteiger JA, Kuphal KE, Magee LM, et al. (2000) Carbohydrate supplementation attenuates muscle glycogen loss during acute bouts of resistance exercise. Int J Sport Nutr Exerc Metab 10: 326-339.

33. Leveritt M, Abernethy PJ (1999) Effects of carbohydrate restriction on strength performance. J Strength Cond Res 13: 52-57.

34. Lambert CP, Flynn MG, Boone JB, Michaud TJ, Rodriguez-Zayas J (1991) Effects of carbohydrate feeding on multiple-bout resistance exercise. J Apply Sport Sci Res 5: 192-197.

35. Haff GG, Stone MH, Warren BJ, Keith R, Johnson RL et al. (1999) The effect of carbohydrate supplementation on multiple sessions and bouts of resistance exercise. J Strength Cond Res 13: 111-117.

36. Haff GG, Schroeder CA, Koch AJ, Kuphal KE, Comeau MJ, et al. (2001) The effects of supplemental carbohydrate ingestion on intermittent isokinetic leg exercise. J Sports Med Phys Fitness 41: 216-222.

37. Conley MS, Stone MH, Marsit JL, O'Bryant HS, Nieman DC, et al. (1995) Effects of carbohydrate ingestion on resistance exercise. J Strength Cond Res 9: 20.

38. Vincet KR, Clarkson PM, Freedson PS, De-Cheke M (1993) Effect of preexercise liquid, high carbohydrate feeding on resistance exercise performance. Med Sci Sport Exerc 25: 194

39. Balsom PD, Söderlund K, Ekblom B (1994) Creatine in humans with special reference to creatine supplementation. Sports Med 18: 268-280.

40. Poortmans JR, Francaux M (1999) Long-term oral creatine supplementation does not impair renal function in healthy athletes. Med Sci Sports Exerc 31 1108-1110.

41. Buford TW, Kreider RB, Stout JR, Greenwood M, Campbell B, et al. (2007) International Society of Sports Nutrition position stand: creatine supplementation and exercise. J Int Soc Sports Nutr 4: 6 .

42. Peeters BM, Lantz CD, Mayhew JL (1999) Effect of oral creatine monohydrate and creatine phosphate supplementation on maximal strength indices, body composition, and blood pressure. J Strength |Cond Res 13: 3-9

43. Tarnopolsky MA, Parise G, Yardley NJ, Ballantyne CS, Olatinji S, et al. (2001) Creatine-dextrose and protein-dextrose induce similar strength gains during training. Med Sci Sports Exerc 33: 2044-2052

44. Greenhaff PL, Bodin K, Soderlund K, Hultman E (1994) Effect of oral creatine supplementation on skeletal muscle phosphocreatine resynthesis. Am $\mathrm{J}$ Physiol 266: E725-730. 
45. Steenge GR, Simpson EJ, Greenhaff PL (2000) Protein- and carbohydrateinduced augmentation of whole body creatine retention in humans. J Appl Physiol (1985) 89: 1165-1171

46. Willoughby DS, Rosene J (2001) Effects of oral creatine and resistance training on myosin heavy chain expression. Med Sci Sports Exerc 33: 1674-1681.

47. Willoughby DS, Rosene JM (2003) Effects of oral creatine and resistance training on myogenic regulatory factor expression. Med Sci Sports Exerc 35: 923-929.

48. Spillane M, Schoch R, Cooke M, Harvey T, Greenwood M, et al. (2009) The effects of creatine ethyl ester supplementation combined with heavy resistance training on body composition, muscle performance, and serum and muscle creatine levels. J Int Soc Sports Nutr 6: 6.

49. O'Connor DM, Crowe MJ (2007) Effects of six weeks of beta-hydroxy-betamethylbutyrate (HMB) and $\mathrm{HMB}$ /creatine supplementation on strength, power and anthropometry of highly trained athletes. J Strength Cond Res 21: 419-423.

50. Easton C, Turner S, Pitsiladis YP (2007) Creatine and glycerol hyperhydration in trained subjects before exercise in the heat. Int $\mathrm{J}$ Sport Nutr Exerc Metab 17: 70-91.

51. Pittas G, Hazell MD, Simpson EJ, Greenhaff PL (2010) Optimization of insulinmediated creatine retention during creatine feeding in humans. J Sports Sci 28: 67-74.

52. Cribb PJ, Williams AD, Stathis CG, Carey MF, Hayes A (2007) Effects of whey isolate, creatine, and resistance training on muscle hypertrophy. Med Sci Sports Exerc 39: 298-307.

53. Suzuki Y, Ito O, Mukai N, Takahashi H, Takamatsu K (2002) High level of skeletal muscle carnosine contributes to the latter half of exercise performance during 30-s maximal cycle ergometer sprinting. Jpn J Physiol 52: 199-205.

54. Dunnett M, Harris RC (1999) Influence of oral beta-alanine and L-histidine supplementation on the carnosine content of the gluteus medius. Equine Vet J Suppl : 499-504.

55. Van Thienen R, Van Proeyen K, Vanden Eynde B, Puype J, Lefere T, et al. (2009) Beta-alanine improves sprint performance in endurance cycling. Med Sci Sports Exerc 41: 898-903.

56. Hoffman JR, Ratamess NA, Ross R, Shanklin M, Kang J, et al. (2008) Effect of a pre-exercise energy supplement on the acute hormonal response to resistance exercise. J Strength Cond Res 22: 874-882.

57. Kendrick IP, Harris RC, Kim HJ, Kim CK, Dang VH, et al. (2008) The effects of 10 weeks of resistance training combined with beta-alanine supplementation on whole body strength, force production, muscular endurance and body composition. Amino Acids 34: 547-554.
58. Portington KJ, Pascoe DD, Webster MJ, Anderson LH, Rutland RR, et al. (1998) Effect of induced alkalosis on exhaustive leg press performance. Med Sci Sports Exerc 30: 523-528.

59. Artioli GG, Gualano B, Coelho DF, Benatti FB, Gailey AW, et al. (2007) Does sodium-bicarbonate ingestion improve simulated judo performance? Int J Sport Nutr Exerc Metab 17: 206-217.

60. Hoffman J, Ratamess NA, Ross R, Kang J, Magrelli J, et al. (2008) Betaalanine and the hormonal response to exercise. Int J Sports Med 29: 952-958.

61. Plaskett CJ, Cafarelli E (2001) Caffeine increases endurance and attenuates force sensation during submaximal isometric contractions. J Appl Physiol (1985) 91: 1535-1544.

62. Woolf K, Bidwell WK, Carlson AG (2008) The effect of caffeine as an ergogenic aid in anaerobic exercise. Int J Sport Nutr Exerc Metab 18: 412-429.

63. Williams AD, Cribb PJ, Cooke MB, Hayes A (2008) The effect of ephedra and caffeine on maximal strength and power in resistance-trained athletes. $J$ Strength Cond Res 22: 464-470.

64. Duncan MJ, Stanley M, Parkhouse N, Cook K, Smith M (2013) Acute caffeine ingestion enhances strength performance and reduces perceived exertion and muscle pain perception during resistance exercise. Eur J Sport Sci 13: 392399.

65. Astorino TA, Roberson DW (2010) Efficacy of acute caffeine ingestion for shortterm high-intensity exercise performance: a systematic review. J Strength Cond Res 24: 257-265.

66. Grant DM, Tang BK, Kalow W (1983) Variability in caffeine metabolism. Clin Pharmacol Ther 33: 591-602.

67. Larsen FJ, Weitzberg E, Lundberg JO, Ekblom B (2007) Effects of dietary nitrate on oxygen cost during exercise. Acta Physiol (Oxf) 191: 59-66.

68. Wilkerson DP, Hayward GM, Bailey SJ, Vanhatalo A, Blackwell JR, et al (2012) Influence of acute dietary nitrate supplementation on 50 mile time tria performance in well-trained cyclists. Eur J Appl Physiol 112: 4127-4134.

69. Jones AM (2013) Dietary Nitrate: the new magic bullet? Sports Sci Ex 26: 1-5.

70. Vanhatalo A, Bailey SJ, Blackwell JR, DiMenna FJ, Pavey TG, et al. (2010) Acute and chronic effects of dietary nitrate supplementation on blood pressure and the physiological responses to moderate-intensity and incremental exercise. Am J Physiol Regul Integr Comp Physiol 299: R1121-1131.

71. Kelly J, Vanhatalo A, Wilkerson DP, Wylie LJ, Jones AM (2013) Effects of nitrate on the power-duration relationship for severe-intensity exercise. Med Sci Sports Exerc 45: 1798-1806. 